\title{
Triple valve endocarditis: the case for multiple valve replacement
}

\author{
Uberto Bortolotti ${ }^{1}$ \\ Received: 28 October 2020 / Accepted: 23 December 2020 / Published online: 8 January 2021 \\ (c) The Japanese Association for Thoracic Surgery 2021
}

\section{To the Editor}

Infection of a cardiac valve or a valvular prosthesis still represents a major surgical problem often requiring complex approaches, mainly depending on clinical status at presentation and pathological findings at operation. Endocarditis in most cases affects one of the cardiac valves, while simultaneous infection of two valves is more infrequent and involvement of three valves, requiring triple prosthetic replacement, is exceedingly rare. For this reason, I read with great interest the paper by Furukawa et al., published in the November 2020 issue of the General Thoracic and Cardiovascular Surgery [1]. The authors report a patient in whom endocarditis involved the aortic, mitral, and tricuspid valves with diffuse vegetations due to $\alpha$-Streptococcus species infection. The aortic and mitral valves were considered not amenable to repair, and both were replaced with pericardial bioprostheses, while tricuspid valve repair was initially performed; persistence of significant tricuspid regurgitation after release of the aortic cross-clamp mandated replacement also of the tricuspid valve with a bioprosthesis, so that the patient ended up with a triple valve replacement.

The experience reported by Furukawa et al. brings me back to more than 40 years ago when I was a young resident at the University of Padua. At that time, we observed a similar case having performed emergency triple valve replacement in a patient with bacterial endocarditis; complete atrio-ventricular block ensued postoperatively requiring also implant of a permanent pacemaker [2]. It is interesting to note that the patient we reported in the late 1970 s was probably one of the first cases of valve involvement by endocarditis requiring triple valve replacement; since then,
I do not remember to have seen a similar case anymore in my long surgical activity. In those years, mitral and tricuspid valve repair for infection-related incompetence was not yet commonplace, as today when also owing to the use of biological or synthetic material, such as pericardial patches or even artificial chordae, the need for replacing infected mitral or tricuspid valves has been reduced [3, 4].

My personal experience, coupled with what observed by Furukawa et al., confirms that simultaneous involvement of three cardiac valves in the setting of infective endocarditis is certainly very unusual. When valvular leaflets are severely damaged, triple prosthetic valve replacement appears to be the only effective solution.

\section{References}

1. Furukawa H, Honda T, Yamasawa T, Kanaoka Y, Tanemoto K. A surgical case of triple valve replacement for triple valve endocarditis with multiple vegetations. Gen Thorac Cardiovas Surg. 2020;68:1333-6.

2. Bortolotti U, Casarotto D, de Mozzi P, Gallucci V, Russo R, Cévese PG. Acute bacterial endocarditis requiring emergency triple valve replacement and pace-maker implant. J Cardiovasc Surg. 1979;20:587-90.

3. Pratali S, Nardi C, Di Gregorio O, Becherini F, Milano A, Bortolotti $\mathrm{U}$. Combined mitral and tricuspid valve repair in acute infective endocarditis. J Heart Valve Dis. 1999;8:447-9.

4. De Martino A, Milano AD, Bortolotti U. Use of pericardium for cardiac reconstruction procedures in acquired heart diseases-a comprehensive review. Thorac Cardiovasc Surg. 2020. https://doi. org/10.1055/s-0039-1697918.

Publisher's Note Springer Nature remains neutral with regard to jurisdictional claims in published maps and institutional affiliations.
Uberto Bortolotti

uberto48@gmail.com

1 Former Head, Section of Cardiac Surgery, University Hospital, Pisa, Italy 